\title{
Pulmonary cell reactions after exposure to cotton dust extract
}

\author{
RAGN'AR RYLANDER and ANNIE NORDSTRAND
}

Institutes of Hygiene, Karolinska Institute, Stockholm and Göteborg University, and Division of Environmental Medicine, Institute for Social and Preventive Medicine, University of Geneva

\begin{abstract}
Rylander, R. and Nordstrand, Annie (1974). British Journal of Industrial Medicine, 31, 220-223. Pulmonary cell reactions after exposure to cotton dust extract. Free lung cells were studied in guinea-pigs exposed to a water extract of cotton mill dust. An increase in the number of leucocytes was found 5 hours after exposure with a peak after about 20 hours. The response was related to the concentration of the extract and was equal in conventional and infectioncontrolled animals. The reaction provides a useful tool for further studies of the toxicity of various fractions of cotton dust.
\end{abstract}

Dust in cotton mills is an industrial air pollutant which has been found to cause a specific chronic lung disease-byssinosis. The incidence of the disease is high among workers in cardrooms and it is frequently accompanied by chronic bronchitis (Fox, Tombleson, Watt, and Wilkie, 1973; Merchant et al., 1973). The clinical features of byssinosis are well known but what is not clear is the cellular reactions initiating the development of the disease or the substance responsible for the toxic effect on the lung.

Kilburn, Lynn, Tres, and McKenzie (1973) have demonstrated an increase in the number of polymorphonuclear leucocytes in the walls of the small bronchi in hamsters exposed to aerosols of crude and refined water extracts of cotton mill thrash. An increased number of leucocytes has also been demonstrated in nasal swabs of humans who had worked for a few hours in the cardroom of a cotton mill (Kilburn, 1973).

As the mobilization of leucocytes into tissue is probably caused by cell injury, the leucocytemobilizing process could be used as an index of the toxicity of inhaled extracts.

The present experiments were undertaken to study in a quantitative way the ability of a water extract of cotton mill dust to mobilize leucocytes in airway lavage preparations. The determinations were performed at various times after a single exposure to different dilutions of the extract as well as after repeated exposures. The reaction in infectioncontrolled (SPF) animals was compared to that in conventional animals.

\section{Material and methods}

The extract was prepared using dust from cotton mill cardroom floor sweepings. Twenty-five milligrams of the dust was placed on filter paper and $150 \mathrm{ml}$ of distilled water was then poured over the dust. The process was performed at room temperature and required about 10 minutes. The elutrient was brownish-yellow with a pH of 6.5-8.4. In certain experiments this dust extract was diluted.

A reproducible deposition in the lungs can be achieved by adding a suspension of particles to the fluid. During aerosolization the particles will, after the dehydration process, carry a coating of the active agent and cause reproducible deposition of the material in the airways. In previous experiments (Rylander, 1968) killed formaldehyde-treated Escherichia coli were used and it was shown that they behaved like inert particles in the lungs.

A culture of $E$. coli was grown overnight on endo-agar plates and suspended in 15\% formaldehyde in saline and then the suspension was centrifuged and washed with saline three times. The killed $E$. coli were added to the different dilutions of the dust extract to yield a concentration of 3.6.10 bacteria/ml. The dust extract was aerosolized with the aid of a Collison spray.

Full-grown infection-controlled (SPF) guinea-pigs 
obtained from Åkers Styckebruk, Sweden, and conventional animals from ordinary dealers were used. The mean weight of the animals was $320 \mathrm{~g}$. The animals were exposed to the aerosol in a stainless steel exposure chamber for $\mathbf{4 0}$ minutes. Control animals were exposed to the $E$. coli suspension only. The number of free lung cells was determined at various times after the cessation of exposure.

The technique to determine the number of free lung cells has already been described (Rylander, 1971). The animals were killed with an intraperitoneal injection of sodium pentothal and the trachea was opened. A small needle was inserted into the trachea and $10 \mathrm{ml}$ of sterile saline was gently flushed into the lungs. The fluid was then withdrawn into the syringe and flushed into the lungs again. This procedure was repeated 10 times, after which the fluid was transferred from the syringe into a glass tube and stained with Türck's stain. The number of cells in the preparation was counted with a Bürcker haematometer and a differentiation was made between macrophages and leucocytes.

Histological preparations were prepared from animals not subjected to the lavage procedure; $10 \mathrm{ml}$ of buffered formaldehyde solution was gently flushed into the lungs. The trachea was then ligated immediately below the larynx and the lungs were dissected from the body. After conventional fixing and embedding, sections were prepared from the different lung lobes, the lobes being cut so that the major bronchi could be followed out towards the periphery. The sections were stained with haematoxylin and eosin.

\section{Results}

Exposure to the undiluted cotton dust extract occasionally caused respiratory distress symptoms in some animals. They developed difficulty in breathing and in a few cases the animals died a few hours after exposure. No difference was observed between conventional and infection-controlled animals.

No increase was found in the number of macrophages and leucocytes exposed to the suspension of formaldehyde-treated $E$. coli. The results from animals exposed to the cotton dust extract were therefore compared with the results from untreated animals from the same delivery. The results of exposure to undiluted dust extract at various times after exposure are reported in Table 1.

It is seen that exposure to cotton dust extract caused an increase in the number of leucocytes which was first noted 3 hours after the exposure. A maximum was reached at 18-24 hours after exposure, after which the number of leucocytes decreased slowly. An increase compared to the controls was still present 92 hours after exposure.

The number of macrophages decreased after exposure and remained low until 18 hours afterwards when an increase was found up to 92 hours, the number then being almost double that of the control animals.

The results from experiments in which different
TABLE 1

Mean Number of Leucocytes and MacroPHAGES IN Lungs OF Guinea-PIGS AT Different Times AFTER EXPOSURE to UNDILUTED COTTON DUST EXTRACT

\begin{tabular}{c|cc|c}
\hline $\begin{array}{c}\text { Hours after } \\
\text { exposure }\end{array}$ & Macrophages & Leucocytes & $\begin{array}{c}\text { Number of } \\
\text { animals }\end{array}$ \\
\hline Control & $130(49)$ & $92(43)$ & 27 \\
1 & $106(52)$ & $97(36)$ & 5 \\
3 & $58(17)$ & $315(137)$ & 5 \\
5 & $42(4)$ & $341(110)$ & 5 \\
18 & $41(38)$ & $836(552)$ & 5 \\
24 & $131(64)$ & $807(224)$ & 11 \\
48 & $198(90)$ & $462(201)$ & 5 \\
92 & $213(60)$ & $328(125)$ & 5 \\
\hline
\end{tabular}

Figures in parentheses indicate standard deviation. The results are illustrated in the Figure.

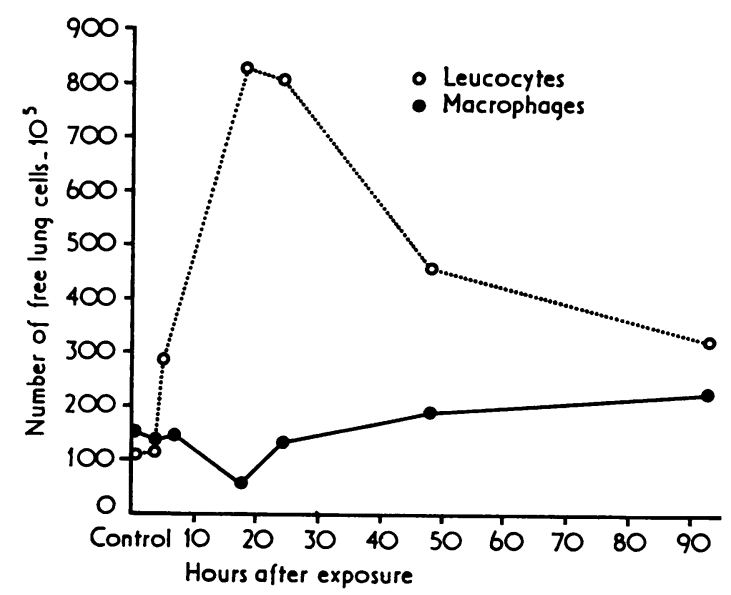

FIGURE Number of macrophages and leucocytes in airway washings from guinea-pigs various times after exposure to a cotton thrash water extract.

dilutions of cotton extract were studied are reported in Table 2.

It is seen that the more concentrated extracts caused a higher increase in the number of leucocytes. This dose-response relationship was not found for macrophages.

The results from experiments in which the reactions in infection-controlled animals and conventional animals were compared are found in Table 3.

It is seen in Table 3 that the number of macrophages and leucocytes in non-exposed conventional and infection-controlled animals was different. The number of the two cell types was about twice as large in the conventional animals. 
TABLE 2

NuMber OF MACROPHAGES AND LeUCOCYTES IN LUNGS OF GUINEA-PIGS EXPOSED TO DIFFERENT Dilutions of CotTon Dust Extract 24 Hours AFTER EXPOSURE

\begin{tabular}{c|cc}
\hline Dilution & Macrophages & Leucocytes \\
\hline 0 & $93(34)$ & $1234(161)$ \\
$1 / 2$ & $90(20)$ & $813(181)$ \\
$1 / 4$ & $101(23)$ & $580(101)$ \\
$1 / 8$ & $75(33)$ & $365(121)$ \\
\hline
\end{tabular}

Mean from three animals at each dilution. Figures in parentheses represent standard deviation.

TABLE 3

MACrophages AND LeUCOCYTES IN LUNGS OF INFECTION-CONTROLLED AND CONVENTIONAL ANimals 24 Hours after EXPOSURE to COTTON DUST EXTRACT

\begin{tabular}{|c|c|c|c|}
\hline & & Macrophages & Leucocytes \\
\hline Conventional & $\begin{array}{l}\text { Control } \\
\text { Exposed }\end{array}$ & $\begin{array}{r}120(45) \\
97(54)\end{array}$ & $\begin{array}{l}100(50) \\
931(450)\end{array}$ \\
\hline $\begin{array}{l}\text { Infection- } \\
\text { controlled }\end{array}$ & $\begin{array}{l}\text { Control } \\
\text { Exposed }\end{array}$ & $\begin{array}{l}48(12) \\
88(39)\end{array}$ & $\begin{array}{c}46(29) \\
1193(750)\end{array}$ \\
\hline
\end{tabular}

Mean from 10 animals in each group. Figures in parentheses represent standard deviation.

In animals exposed to cotton dust extract, a significant increase in the number of leucocytes was found in both conventional and infection-controlled animals. Considering the rather large variation between animals, no appreciable difference was noted between the extent of the leucocyte increase in the conventional and infection-controlled animals.

The number of macrophages was affected only in the infection-controlled animals where a statistically significant increase was found.

The results from the experiments where animals were exposed to the cotton extract at intervals of 24 hours are reported in Table 4.

It is seen in Table 4 that a repeated exposure 24, 48, and 72 hours after the previous one produced a further increase in the number of leucocytes.

An evaluation of the histological section showed few polymorphonuclear cells in the bronchi or airway lumen of the control guinea-pigs. In the exposed animals alveoli and smaller airways contained a large number of polymorphonuclear leucocytes which were also seen on the surface of the trachea. The cells were present between epithelial cells at all levels of the respiratory tree but seemed to be more abundant in smaller airways.
TABLE 4

Number of MACROPHAges AND LeUCOCYTES IN GuINEA-PIGS 24 Hours AFTER RePEATED EXPOSURES TO COTTON DUST EXTRACT

\begin{tabular}{l|cc}
\hline & Macrophages & Leucocytes \\
\hline Control & $143(38)$ & $78(36)$ \\
Exposure 1 & $117(53)$ & $1232(70)$ \\
+ Exposure 2 (24 hours) & $131(53)$ & $1390(638)$ \\
+ Exposure 3 (24 hours) & $206(40)$ & $2131(726)$ \\
\hline
\end{tabular}

Mean from five to eight animals. Figures in parentheses represent standard deviation.

\section{Discussion}

The technique used in the present experiment to determine the number of free lung cells has been shown to yield reproducible results and sample all levels of the respiratory tree (Rylander, 1971). The number of cells is affected by the number of washings but provided that this is standardized and exceeds seven, the influence of this experimental error is decreased. It has been shown in experiments measuring the deposition of radioactively labelled $E$. coli that prior exposure to agents which might cause bronchoconstriction does not affect the accuracy of the lavage procedure if this is performed two hours after the cessation of exposure.

Animals exposed to the suspension of $E$. coli only did not show any increase in the number of leucocytes. It is well known that viable $E$. coli or the supernatant from the cultures exert a strong leucotoxic effect when injected into animals or when inhaled. In the present procedure, however, the cell walls were fixed by the formaldehyde in the suspension and the bacterial culture was washed and centrifuged three times. The extracellular substances in the original culture were thus efficiently removed.

The increase in the number of leucocytes demonstrated in histological sections of small airways by Kilburn et al. (1973) suggested that an increase in the number of leucocytes in the large airways might also occur. The present experiment has demonstrated that this increase does take place. Similar increases were also found in rats, hamsters, and rabbits exposed to the same extract.

The results from the experiment in which various dilutions from the extract were used shows that the reaction can be used as a quantitative mean to measure the effect of exposure.

The results from experiments performed at various times after exposure demonstrated that a maximum reaction was reached in 18-24 hours. This did not represent an absolute maximum as repeated exposures were shown to increase the number of leucocytes even further. In contrast to the leucocytes 
the number of macrophages was only marginally affected by the dust extract exposure.

As exposure to the cotton dust extract caused an increase in the number of leucocytes in airways, a possible mode of action could be an immediate cell process with a release of intracellular enzymes which call for a mobilization of leucocytes to the damaged tissue. The release of histamine is also involved in the process. It is not known whether this effect was mediated by macrophages or by the epithelial tissue itself.

The extent of the leucocyte reaction was not affected by the presence of latent respiratory infection as shown in experiments where the reaction in infection-controlled animals was compared to that in conventional animals. In contrast, it has been shown in experiments using air pollution models that the extent of other kinds of lung damage from inhaled agents might be affected by the state of infection of the animal used (Bell and Elmes, 1965; Creasia, Nettesheim, and Hammons, 1973; Rylander and Bergström, 1973).

A study of the histological sections of animals not subjected to the lavage procedure did not reveal the portal of entry of leucocytes into the airways. An increased number of leucocytes was found both in small airways and in the alveoli at times when their number has increased in the large airways. In the sections the massive invasion into alveoli favours the importance of this portal of entry.

The relation between the large increase in pulmonary leucocytes after an exposure to cotton dust extract and the development of byssinosis cannot be assessed against the background of available data. It is likely, however, that the influx of leucocytes reflects an increased demand on the immunological defence mechanisms of the exposed organisms. The magnitude of this primary response could then be correlated with the potential of the dust to induce further reactions in the immunological system of the lungs which in turn form the basis for later development of byssinosis.

Several attempts have been made to isolate the agent responsible for the toxic effect of cotton dust. Hitchcock, Piscitelli, and Bouhuys (1973) studied the histamine-releasing properties of extracts from various parts of the cotton plant. The histaminereleasing effect was found to be connected with a compound similar to methyl piperonylate isolated from cotton bracts. The authors concluded that other chemical constituents of the cotton plant might also have a similar effect. Aminopolysaccharides and free sugars are other substances which have been connected with the toxic effect of cotton dust (Mohammed, El-gazzar, and Adamyova, 1971). The role of bacterial endotoxins was supported by results reported by Pernis, Vigliani, Cavagna, and Finulli (1961).
With the experimental model described here it becomes possible to pursue selective toxicity testing of various fractions of the dust and contaminations thereof in acute as well as subchronic exposure experiments.

The study was supported by the United States Department of Agriculture with funds made available through Cotton Incorporated.

\section{References}

Bell, D. P. and Elmes, P. C. (1965). The effects of chlorine gas on the lungs of rats without spontaneous pulmonary disease. Journal of Pathology and Bacteriology, 89, 307-317.

Creasia, D. A., Nettesheim, P., and Hammons, A. S. (1973). Impairment of deep lung clearance by influenza virus infection. Archives of Environmental Health, 26, 197-201.

Fox, A. J., Tombleson, J. B. L., Watt, A., and Wilkie, A. G. (1973). A survey of respiratory disease in cotton operatives. British Journal of Industrial Medicine, 30, 42-53.

Hitchcock, M., Piscitelli, D. M., and Bouhuys, A. (1973). Histamine release from human lung by a component of cotton bracts. Archives of Environmental Health, 26, 177-182.

Kilburn, K. H. (1973). Personal communication.

- Lynn, W. S., Tres, L. L., and McKenzie, W. N. (1973). Leucocyte recruitment through airway walls by condensed vegetable tannins and quercetin. Laboratory Investigation, 28, 55-59.

Merchant, J. A., Lumsden, J. C., Kilburn, K. H., O'Fallon, W. M., Ujda, J. R., Germino, V. H., and Hamilton, J. D. (1973). Dose response studies in cotton textile workers. Journal of Occupational Medicine, 15, 222-230.

Mohammed, Y. S., El-Gazzar, R. M., and Adamyova, K. (1971). Byssinosan, an aminopolysaccharide isolated from cotton dust. Carbohydrate Research, 20, 431-435.

Pernis, B., Vigliani, E. C., Cavagna, C., and Finulli, M. (1961). The role of bacterial endotoxins in occupational diseases caused by inhaling vegetable dusts. British Journal of Industrial Medicine, 18, 120-129.

Rylander, R. (1968). Pulmonary defence mechanisms to airborne bacteria. Acta Physiologica Scandinavica, Supplement 306, p. 1-89.

- (1971). Free lung cell studies in cigarette smoke inhalation experiments. Scandinavian Journal of Respiratory Diseases, 52, 121-128.

- and Bergström, R. (1973). Particles and $\mathrm{SO}_{2}$ synergistic effects for pulmonary damage. Proceedings of the Third International Clean Air Congress, Düsseldorf, 1973, pp. A 23-25. VDI Verlag.

Received for publication 8 October 1973 